NASA/TM-1998-206555

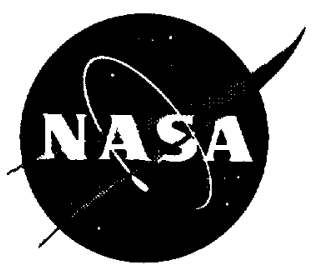

\title{
Thermal Analysis of a Metallic Wing Glove for a Mach-8 Boundary-Layer Experiment
}

Leslie Gong and W. Lance Richards

Dryden Flight Research Center

Edwards, California

National Aeronautics and

Space Administration

Dryden Flight Research Center

Edwards, California 93523-0273 


\section{NOTICE}

Use of trade names or names of manufacturers in this document does not constitute an official endorsement of such products or manufacturers, either expressed or implied, by the National Aeronautics and Space Administration.

Available from the following:

NASA Center for AeroSpace Information (CASI)

National Technical Information Service (NTIS)

5285 Port Royal Road

7121 Standard Drive

Hanover, MD 21076-1320

Springfield, VA 22161-2171

(301) 621-0390

(703) $487-4650$ 


\title{
THERMAL ANALYSIS OF A METALLIC WING GLOVE FOR A MACH-8 BOUNDARY-LAYER EXPERIMENT
}

\author{
Leslie Gong ${ }^{*}$ and W. Lance Richards ${ }^{\dagger}$ \\ NASA Dryden Flight Research Center \\ Edwards, CA
}

\begin{abstract}
$\underline{\text { Abstract }}$
A metallic "glove" structure has been built and attached to the wing of the Pegasus ${ }^{(1)}$ space booster. An experiment on the upper surface of the glove has been designed to help validate boundary-layer stability codes in a free-flight environment. Three-dimensional thermal analyses have been performed to ensure that the glove structure design would be within allowable temperature limits in the experiment test section of the upper skin of the glove. Temperature results obtained from the designcase analysis show a peak temperature at the leading edge of $490{ }^{\circ} \mathrm{F}$. For the upper surface of the glove, approximately 3 in. back from the leading edge, temperature calculations indicate transition occurs at approximately $45 \mathrm{sec}$ into the flight profile. A worst-case heating analysis has also been performed to ensure that the glove structure would not have any detrimental effects on the primary objective of the Pegasus ${ }^{\circledR}$ launch. A peak temperature of $805^{\circ} \mathrm{F}$ has been calculated on the leading edge of the glove structure. The temperatures predicted from the design case are well within the temperature limits of the glove structure, and the worstcase heating analysis temperature results are acceptable for the mission objectives.
\end{abstract}

\section{$\underline{\text { Nomenclature }}$}

$\begin{array}{ll}C & \text { solar and nocturnal radiation input, } \frac{\mathrm{Btu}}{\mathrm{ft}^{2} / \mathrm{sec}} \\ C p & \text { specific heat, } \frac{\mathrm{Btu}}{\mathrm{lbm} \cdot{ }^{\circ} \mathrm{F}} \\ \mathrm{F} & \text { magnification factor } \\ h & \text { local heat-transfer coefficient based on } \\ & \text { enthalpy, } \frac{\mathrm{lbm}}{\mathrm{ft}^{2} / \mathrm{sec}} \\ H & \text { enthalpy, } \mathrm{Btu} / \mathrm{bm}\end{array}$

\footnotetext{
*Aerospace Engineer.

Aerospace Engineer.

Copyright (c) 1998 by the American Institute of Aeronautics and Astronautics, Inc. No copyright is asserted in the United States under Title 17, U.S. Code. The U.S. Government has a royalty-free license to exercise all rights under the copyright claimed herein for Governmental purposes. All other rights are reserved by the copyright owner.
}

\author{
$H_{r} \quad$ recovery enthalpy (for stagnation point use \\ $H_{\mathrm{s}}$, stagnation enthalpy) \\ $\mathrm{M}_{\mathrm{L}} \quad$ local Mach number \\ $\mathrm{Re}_{\mathrm{L}} \quad$ local Reynolds number \\ $\operatorname{Re}_{\text {TRN transition Reynolds number }}$ \\ SPAR Structural Performance and Resizing \\ SWAS Submillimeter Wave Astronomy Satellite \\ $T \quad$ temperature, ${ }^{\circ} \mathrm{F}$ \\ $t \quad$ flight time, sec \\ TPATH theoretical thin-skin aerodynamic heating \\ program (NASA Dryden computer \\ program) \\ $x \quad$ flow distance, $\mathrm{ft}$ \\ $v \quad$ velocity, $\mathrm{ft} / \mathrm{sec}$ \\ $\frac{d T w}{d t} \quad$ rate of change of wall temperature, ${ }^{\circ} \mathrm{F} / \mathrm{sec}$ \\ $\alpha \quad$ angle of attack, deg \\ $\beta \quad$ Stefan-Boltzman constant, $\frac{\mathrm{Btu}}{\mathrm{hr} \cdot \mathrm{ft}^{2} \cdot{ }^{\circ} \mathrm{R}^{4}}$ \\ $\Delta T \quad$ temperature difference, ${ }^{\circ} \mathrm{F}$ \\ $\delta \quad$ skin thickness, $\mathrm{ft}$ \\ $\rho$ density, $\mathrm{lbm} / \mathrm{ft}^{3}$ \\ Subscripts

$\begin{array}{ll}\text { r } & \text { boundary-layer recovery } \\ \text { s } & \text { stagnation } \\ \text { w } & \text { wall } \\ \text { i } & \text { value based on enthalpy } \\ & \text { Introduction }\end{array}$

For decades, predicting accurate boundary-layer transition has been a complicated and difficult endeavor. 
Accurate boundary-layer transition criteria can make or break high-speed aircraft designs. The overdesign of the structure can produce low thermal stresses but with an excessive weight penalty, or the underdesign of the structure can result from an overzealous determination of the extent of laminar flow in the boundary layer. Underdesign may cause the structure to thermally buckle and result in a catastrophic failure. A practical way of gaining insight into boundary-layer transition can be attained through experimental flight test with vehicles such as the Pegasus ${ }^{\text {(O) }}$ (Orbital Sciences Corporation, Fairfax, Virginia) space booster. The primary purpose of this experiment is to support the current efforts in validating boundary-layer stability codes at high Mach numbers.

A metallic glove has been fabricated and instrumented for the wing of the Pegasus ${ }^{\otimes}$ booster rocket. Temperature measurements will be made to determine boundary-layer transition location on the metallic skin surface.

Calculated temperature predictions have been produced using a three-dimensional finite-element thermal model of the wing glove. The thermal analyses have been performed using a finite-element thermal analysis code called the Structural Performance and Resizing (SPAR) program. ${ }^{1}$

Various thermal analyses were performed to ensure the safe design of the glove structure, provide temperature distributions for additional thermal stress analyses, and qualify the glove structure for flight. Heating rates used in the SPAR program are calculated using a NASA Dryden Flight Research Center (Edwards, California) in-house code, a theoretical thinskin aerodynamic heating program called TPATH. Results from two different heating cases using the SPAR thermal model are presented in this paper.

\section{Background}

The Pegasus ${ }^{\circledR}$ space booster is an air-launched, threestaged solid rocket designed to deploy payloads weighing a maximum of $1000 \mathrm{lbs}$ into low Earth orbit. Figure 1 shows the physical dimensions of the Pegasus ${ }^{1}$ space booster, the location of the glove structure, and the general trajectory for first-stage burn. The booster has an overall length of approximately $49 \mathrm{ft}$ and a wingspan of $22 \mathrm{ft}$. The cylindrical fuselage is approximately $4.2 \mathrm{ft}$ in diameter. The overall weight of the booster is approximately $42,000 \mathrm{lbm}$. The size, shape, weight, and Mach range of the Pegasus ${ }^{(1)}$ are approximately the same as for the $\mathrm{X}-15$ vehicle.

\section{Glove Design}

Previous thermal analysis work was conducted to determine the glove material selection, skin thickness sizing, and surface temperature response caused by boundary-layer transition. ${ }^{2}$ Details of previous work, including the structural design, finite-element analysis, and ground heating simulation tests, have been published. ${ }^{3-6}$

Figure 2 shows a top-view schematic of the glove and the glove location on the wing of the Pegasus ${ }^{12}$ booster. Figure 3 shows a cutaway view of the glove, which consists of three main sections: a thick leading edge, and upper and lower skins. The thick leading edge provides sufficient heat sink capability to survive the severe aerodynamic heating environment near the stagnation region. The leading edge is rigidly attached to the wing at a single location using four 0.25 -in. steel pins to restrain movement in all directions. To alleviate thermal stresses, however, the leading edge is also attached to the wing through a series of slotted attachments, or guide blocks, that allow the leading edge of the glove to thermally expand in the spanwise direction. At the outboard tip of the glove, a modified guide block is used to restrain the glove leading edge only in the chordwise direction. Substantial details of the design of the attachments and leading edge have previously been published. ${ }^{3}$

The primary Pegasus ${ }^{\circledR}$ glove structure is low-carbon steel that is nickel-plated to protect the surface from corrosion and to provide uniform emissivity. The upper skin of the glove is 0.0890 -in. thick and is joined to the leading edge with an overlap joint, fastened with a double row of 0.1875 -in. machine screws, and then soldered. The solder is primarily used to fill the gap between the skin and the leading-edge structure and to promote heat conduction. The overlap solder joint is located 3 in. back from the leading edge and is 0.5 -in. wide spanning the entire width of the glove. The solder has a melting temperature of $430^{\circ} \mathrm{F}$. Because the lower surface of the glove is not essential for the boundarylayer experiment, latitude has been given for attachment method and skin thickness. The lower skin thickness is $0.125 \mathrm{in}$.

The upper and lower thin skins are held against a contoured balsa wood foundation using a series of spring-loaded swivel-stud assemblies (fig. 3). Figure 4 shows an enlarged view of the swivel-stud assembly. The swivel studs are preloaded with enough force to hold the skin down normal to the contoured balsa wood surface but still allow the skin to thermally expand along the 
skin/balsa interface. The swivel studs are bonded to the inner skin of the glove, and the balsa wood blocks are bonded to the Pegasus ${ }^{\circledR}$ wing.

\section{Glove Instrumentation}

Glove instrumentation includes thermocouples, staticpressure ports, Preston tubes, Stanton gages, accelerometers, hot films, strain gages, and a boundarylayer rake with thermocouples, most of which are installed on the upper surface of the glove structure. Figure 2 shows the locations for three rows of thermocouples and pressure ports instrumentation.

\section{Thermal Analysis Boundary Conditions}

Figure 5 shows the trajectory for the first stage of the Pegasus ${ }^{\circledR}$ space booster. This trajectory was intended for the launch of the Submillimeter Wave Astronomy Satellite (SWAS) and is the trajectory used for these analyses. Flight time, $t$, is $0 \mathrm{sec}$ at the release of booster from the carrier aircraft, and first-stage burn lasts for $69 \mathrm{sec}$. The Pegasus ${ }^{\circledR}$ booster reaches an altitude of $200,000 \mathrm{ft}$ and a velocity of $8327 \mathrm{ft} / \mathrm{sec}$ before first-stage separation occurs at $t=79 \mathrm{sec}$.

Aerodynamic heating rates based on the SWAS trajectory for the various locations on the glove structure (or thermal model locations) have been computed with a NASA Dryden in-house computer program called TPATH. The TPATH program was created and used during the X-15 program (1959-1968). The accuracy of the methods used in the TPATH program has been verified by comparisons with measured flight data from the X-15 research vehicle, the YF-12 airplane, and the Space Shuttle Orbiter. ${ }^{7-12}$

The calculated transient-heating rates provided by the TPATH program are used as the heat loads in the SPAR thermal model. The TPATH program uses the outer moldline of the structure to determine expansion angles, wedge angles, flow distances, and the leading-edge radius. A cut at the midspan of the glove was used to obtain the outer moldline.

Points on the outer moldline were selected for heating rate calculations. Locations aft of the tangent point from the leading edge are typically spaced every 1 in., and seven locations are at or near the leading edge. These seven locations are needed to give enough resolution in the heating rates for the number of elements around the leading edge used in the SPAR thermal model. The TPATH code solves the thin skin transientheating equation,

$$
\rho_{\mathrm{w}} C p_{\mathrm{w}} \delta_{\mathrm{w}} \frac{d T w}{d t}=\mathrm{F} h_{\mathrm{i}}\left(H_{r}-H_{\mathrm{w}}\right)-\beta T_{\mathrm{w}}^{4}+C
$$

and provides time histories of surface temperatures, heating rates, and heat-transfer coefficients for selected locations. An individual thermal mass is associated with each location where a heating rate is calculated.

For the TPATH computations, the heating rates can be separated into three categories: the leading-edge area, lower surface of the glove, and upper surface of the glove. The TPATH program gives the user the option of using several approximate convective-heating theories, depending on the geometry of interest. For the leadingedge stagnation point, the Fay and Riddell theory ${ }^{13}$ corrected to two-dimensional flow was used to calculate the stagnation-point heating. Swept cylinder theory was used to determine the local flow conditions around the leading edge. The heating rate distributions around the leading edge to the tangent point used the Lees theory. ${ }^{14}$ For the glove skin aft of the leading-edge tangent point, Eckert's Reference Enthalpy method ${ }^{\text {I5 }}$ was used to calculate the transient-surface heating rates for both laminar and turbulent flow. The local flow conditions aft of the tangent point were computed by the oblique shock theory ${ }^{16}$ using an appropriate wedge angle to approximate the blunt leading edge of the Pegasus ${ }^{(}$ wing. Those results were then used as inputs to the Prandl-Meyer Expansion theory ${ }^{17}$ to calculate downstream local flow values.

Each external surface area of the SPAR thermal model requires a heating rate input. Heating rates for other chordwise locations of the SPAR thermal model were obtained from the same set of heating rate tables calculated for the midspan cut. To obtain the correct heating rate table, the streamwise flow distance, $x$, is measured at the particular chord location from the leading edge, and the corresponding heating rate table is used at the same flow distance at the midspan location. For locations on the SPAR thermal model where a heating rate had not been calculated, the nearest location where a heating rate had been calculated was used.

Figure 6 shows calculated aerodynamic heating rates for various model locations for the design case. All exposed model surface elements were subjected to the appropriate heating rate for the element location. At location $\mathrm{C}$ (the leading edge), a peak heating rate of $26.8 \mathrm{Btu} /\left(\mathrm{ft}^{2} / \mathrm{sec}\right)$ is shown. Moving aft from the leading edge, the peak heating rates are substantially lower. The upper-surface thin skin where the boundary-layer experiment is located is subjected to substantially lower 
heating rates than the lower-surface thin skin because of angle-of-attack effects. Figure 6 shows two calculated heating rate time histories for the upper surface of the glove at locations $\mathrm{D}$ and $\mathrm{E}$. At location $\mathrm{D}$, the heating rate change from turbulent to laminar flow occurs earlier than for location E. The transition criteria used in the TPATH code was based on the combined factors of a transition Reynolds number of 200,000 and a local Mach number multiplier of 0.15 according to the following equations:

$$
\begin{aligned}
& \log R e_{\mathrm{L}}>\log R \mathrm{e}_{\mathrm{TRN}}+0.15 \mathrm{M}_{\mathrm{L}} \text { turbulent flow } \\
& \log \mathrm{Re}_{\mathrm{L}} \leq \log \mathrm{Re}_{\mathrm{TRN}}+0.15 \mathrm{M}_{\mathrm{L}} \text { laminar flow }
\end{aligned}
$$

If the log of the local Reynolds number is higher than the transition criteria, then the equation for turbulent flow is used. If the log of the local Reynolds number is less than or equal to the criteria, then the equation for laminar flow is used.

Two thermal analyses cases are shown in this paper, one considered a design case and the other a worst case. The more severe case has had the leading-edge heating rates artificially magnified by 1.9 , and the transition for the upper and lower surfaces of the glove locations have been suppressed for the majority of the flight trajectory. The worst case was developed to verify that the Pegasus ${ }^{\circledR}$ could still complete its primary payload insertion if the boundary-layer experiment were no longer viable.

\section{Thermal Models}

Figures 7 and 8 show the full, three-dimensional SPAR thermal model used for the entire glove structure. This model consists of 6178 joint locations; 3777 solid, eight-node conduction elements; and 187 solid, six-node conduction elements. Each external surface (on the eight-node or six-node conduction element) exposed to aerodynamic heating has a radiation element applied to the surface to represent the radiation heat loss to space. Internal radiation from the steel glove elements to other internal structural surfaces was not included in this model. The model had 1811 external, four-node radiation elements and 77 external, threenode radiation elements. The swivel studs, wavy springs, balsa wood structure, interfacing internal substructure that connects the glove to the existing Pegasus $^{\otimes}$ wing, and Pegasus ${ }^{\otimes}$ wing were not included in the SPAR thermal model. Aerodynamic heating rates $\left(\mathrm{Btu} /\left(\mathrm{ft}^{2} / \mathrm{sec}\right)\right)$ were applied to the external surface of the SPAR thermal model.

\section{Results and Discussion}

Figure 9 shows a comparison of the SPAR temperature predictions for the design and worst case (the dashed and solid lines, respectively). These locations were taken from a cut perpendicular to the leading edge of the glove model. A peak temperature of $490^{\circ} \mathrm{F}$ (for the design case) can be seen at location $C$ (leading edge) (fig. 9). The worst-case heating analysis shows a leading-edge temperature of $805^{\circ} \mathrm{F}$ at $t=79 \mathrm{sec}$. Figure 9 also shows locations D and E (upper surface) and $A$ and $B$ (lower surface). The design-case temperature curves (fig. 9) for the lower and upper surface of the glove (locations A, B, $\mathrm{D}$, and $\mathrm{E}$ ) all have a slope change in the curves at approximately $45-50 \mathrm{sec}$ into the flight profile. This slope change is an indication that transition from turbulent to laminar flow has occurred.

The transition from turbulent to laminar flow occurs earlier in time closer to the leading edge and moves further aft on the glove structure later in the flight profile. Figure 9 shows peak (design case) temperature values of 404 and $373^{\circ} \mathrm{F}$ for locations $\mathrm{D}$ and $\mathrm{E}$. For the worst case, the temperature predictions for upper and lower surface locations do not show a significant slope change in the temperature curves, because the heating rates used were calculated for turbulent flow for the majority of the flight profile. For location $\mathrm{C}$, the worst-case temperature time history predictions were based on an artificially magnified heating rate at the leading edge.

Figure 10 shows the SPAR temperature time histories predictions for joints 121 and 122 on the upper surface of the glove. Surface joint (or grid point) 121 is located on the thick skin where the thin skin is soldered to the leading edge, and the other surface joint, 122, is on the thin skin (fig. 3). This location on the glove is critical because any melting and flow of solder out of the gap and onto the glove skin can perturb the boundary layer and ruin the experiment. In addition, the joint would be weakened because of a high temperature gradient. As can be seen, the highest temperature gradient occurs towards the end of the first-stage burn. Joints 121 and 122 are still at temperatures less than the solder melt temperature of $430^{\circ} \mathrm{F}$ at $t=79 \mathrm{sec}$.

Another critical location in the design of the glove structure is at the interface between the lower skin and the thick leading edge. Figure 11 shows the predicted temperature time histories at two surface locations on either side of this interface. Time history data at surface joint 6146 , which is located on the thick leading edge, and surface joint 10696, which is located on the thin 
skin, were used to determine the maximum temperature gradient, and when it occurs during the flight. This figure shows that a maximum temperature gradient of $170^{\circ} \mathrm{F} / \mathrm{in}$. is predicted to occur at a trajectory time of $46 \mathrm{sec}$.

Figure 12 shows predicted surface temperatures on the glove using the design-case and worst-case heating rates as a function of distance aft of the leading edge at $t=79 \mathrm{sec}$. This plot indicates the maximum allowable temperature of the solder joint and the allowable temperature of the adhesive used to bond the swivel studs to the wing glove. Figure 12 shows the location of the solder joint ( $3 \mathrm{in}$. back from the leading edge). The solder has a melting temperature of $430^{\circ} \mathrm{F}$. The $520^{\circ} \mathrm{F}$ temperature limit line is the temperature limit of the swivel-stud adhesive. A significant temperature margin is shown for the solder joint for the design case, an acceptable margin is shown for the worst case, and a considerable temperature margin for the adhesive exists.

Another location to verify in the design of the glove is at the location of the first swivel stud attached closest to the leading edge (4.72 in. aft) on the lower glove skin. Figure 13 shows the predicted temperature distribution on the lower glove skin using the worst-case and designcase heating rates for a time slice at $79 \mathrm{sec}$ into the flight profile. At this critical time in the flight profile, the skin temperature at the first swivel stud is well below the adhesive temperature limit line (fig. 13).

\section{Concluding Remarks}

Thermal analyses have been performed for the final design of the Pegasus ${ }^{(B)}$ wing glove intended for a boundary-layer transition experiment. These analyses were performed to provide temperature distributions for thermal stress analyses. Temperature results have been shown from two heating cases, the design case and a worst case. The worst-case analysis was performed to ensure that the glove structure would not fail catastrophically and impair the successful deployment of the Pegasus ${ }^{(B)}$ payload. The analysis for the design case shows that the calculated temperatures are well within the allowable temperature limits for the glove design. At the critical location of the upper-skin solder joint, a maximum temperature of $404^{\circ} \mathrm{F}$ was calculated, which is well within the design temperature limit. Transition from turbulent flow to relaminarization at this location occurs at $45 \mathrm{sec}$ into the flight profile. Temperature values predicted on the glove structure using an artificially magnified heating rate at the leading edge and a significantly longer duration of turbulent flow on the glove are still acceptable.

Surface temperatures on the glove upper skin for a time slice at $79 \mathrm{sec}$ at the solder joint location are below the melting temperature of the solder for both analyses using the worst-case and design-case heating rates. Calculated temperatures at the first swivel-stud attachment location on the lower glove skin are well below the adhesive temperature limit at $79 \mathrm{sec}$ into the flight profile.

\section{References}

${ }^{1}$ Marlowe, M. B., R. A. Moore, and W. D. Whetstone, SPAR Thermal Analysis Processors Reference Manual, System Level 16, NASA CR-159162, 1979.

${ }^{2}$ Gong, Leslie, W. Lance Richards, Richard C. Monaghan, and Robert D. Quinn, Preliminary Analysis for a Mach 8 Crossfiow Transition Experiment on the Pegasus ${ }^{\circledR}$ Space Booster, NASA TM-104272, 1993.

${ }^{3}$ Richards, W. L. and R. C. Monaghan, "Development of a Flight Article for a Hypersonic Boundary-Layer Experiment," Journal of Spacecraft and Rockets, vol. 34, no. 5, May 1997, pp. 609-613.

${ }^{4}$ Richards, W. Lance, Finite-Element Analysis of a Mach-8 Flight Test Article Using Nonlinear Contact Elements, NASA TM-4796, 1997.

${ }^{5}$ Horn, Thomas J., W. Lance Richards, and Leslie Gong, A Technique for Transient Thermal Testing of Thick Structures, NASA TM-4803, 1997.

${ }^{6}$ Bertelrud, Arild, Paul Kolodziej, Greg K. Noffz, and Afzal Godil, "Plans for In-Flight Measurement of Hypersonic Crossflow Transition on the Pegasus ${ }^{\circledR}$ Launch Vehicle," AIAA-92-4104, Aug. 1992.

${ }^{7}$ Banner, Richard D., Albert E. Kuhl, and Robert D. Quinn, Preliminary Results of Aerodynamic Heating Studies on the X-15 Airplane, NASA TM-X-638, 1962.

${ }^{8}$ Gord, P. R., Measured and Calculated Structural Temperature Data From Two X-15 Airplane Flights With Extreme Aerodynamic Heating Conditions, NASA TM-X-1358, 1967.

${ }^{9}$ Watts, Joe D. and Ronald P. Banas, X-15 Structural Temperature Measurements and Calculations for Flights to Maximum Mach Numbers of Approximately 4, 5, and 6, NASA TM-X-883, 1963. 
${ }^{10}$ National Aeronautics and Space Administration, NASA YF-12 Flight Loads Program, NASA TM-X-3061, 1974.

${ }^{11} \mathrm{Ko}$, William L., Robert D. Quinn, and Leslie Gong, Finite-Element Reentry Heat-Transfer Analysis of Space Shuttle Orbiter, NASA TP-2657, 1986.

${ }^{12}$ Gong, Leslie, William L. Ko, Robert D. Quinn, and W. Lance Richards, Comparison of Flight-Measured and Calculated Temperatures on the Space Shuttle Orbiter, NASA TM-88278, 1987.

${ }^{13}$ Fay, J. A. and F. R. Riddell, "Theory of Stagnation Point Heat Transfer in Dissociated Air," Journal of the Aeronautical Sciences, vol. 25, no. 2, Feb. 1958, pp. 73-85.
${ }^{14}$ Lees, Lester, "Laminar Heat Transfer Over BluntNosed Bodies at Hypersonic Flight Speeds," Jet Propulsion: Journal of the American Rocket Society, vol. 26, no. 4, Apr. 1956, pp. 259-274.

${ }^{15}$ Eckert, Ernst R. G., "Survey of Boundary Layer Heat Transfer at High Velocities and High Temperatures," WADC TR-59-624, Wright Air Development Center, Apr. 1960.

${ }^{16}$ Moeckel, W. E., Oblique-Shock Relations at Hypersonic Speeds for Air in Chemical Equilibrium, NACA TN-3895, 1957.

${ }^{17}$ Ames Research Staff, Equations, Tables, and Charts for Compressible Flow, NACA Report 1135, 1953. 


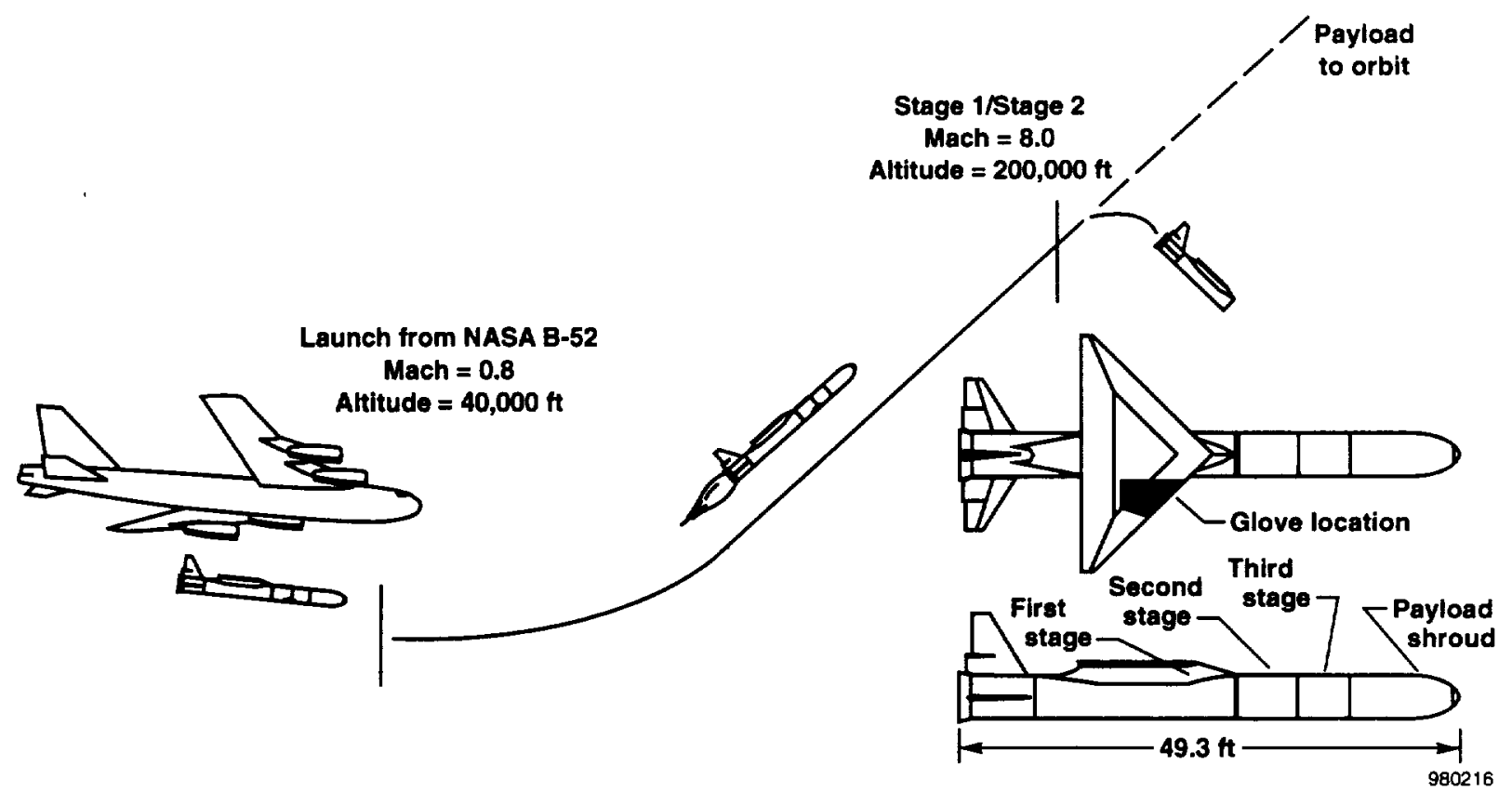

Figure 1. The Pegasus ${ }^{(a u n c h}$ configuration with an insert indicating glove experiment location.
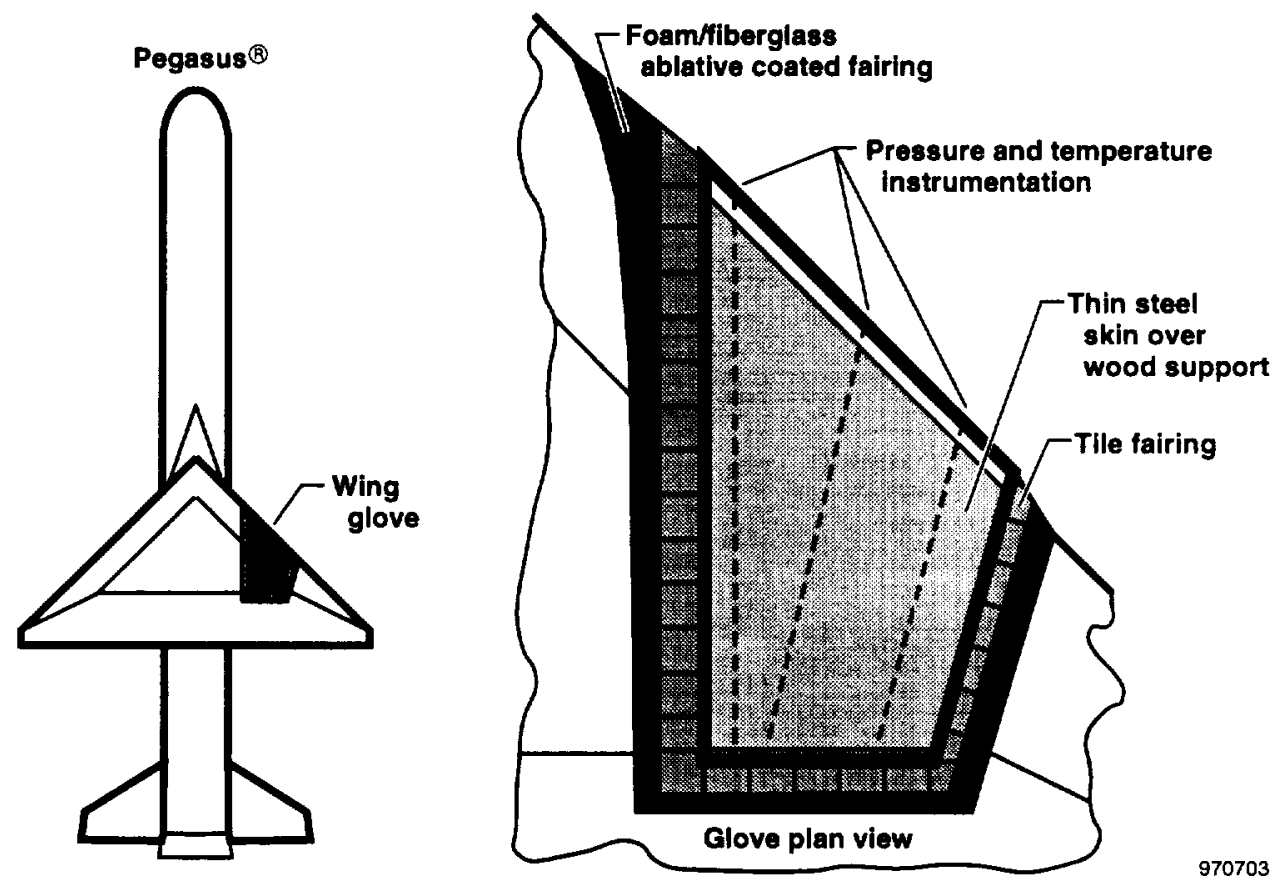

Figure 2. Plan view of the Pegasus ${ }^{\circledR}$ vehicle and test glove. 


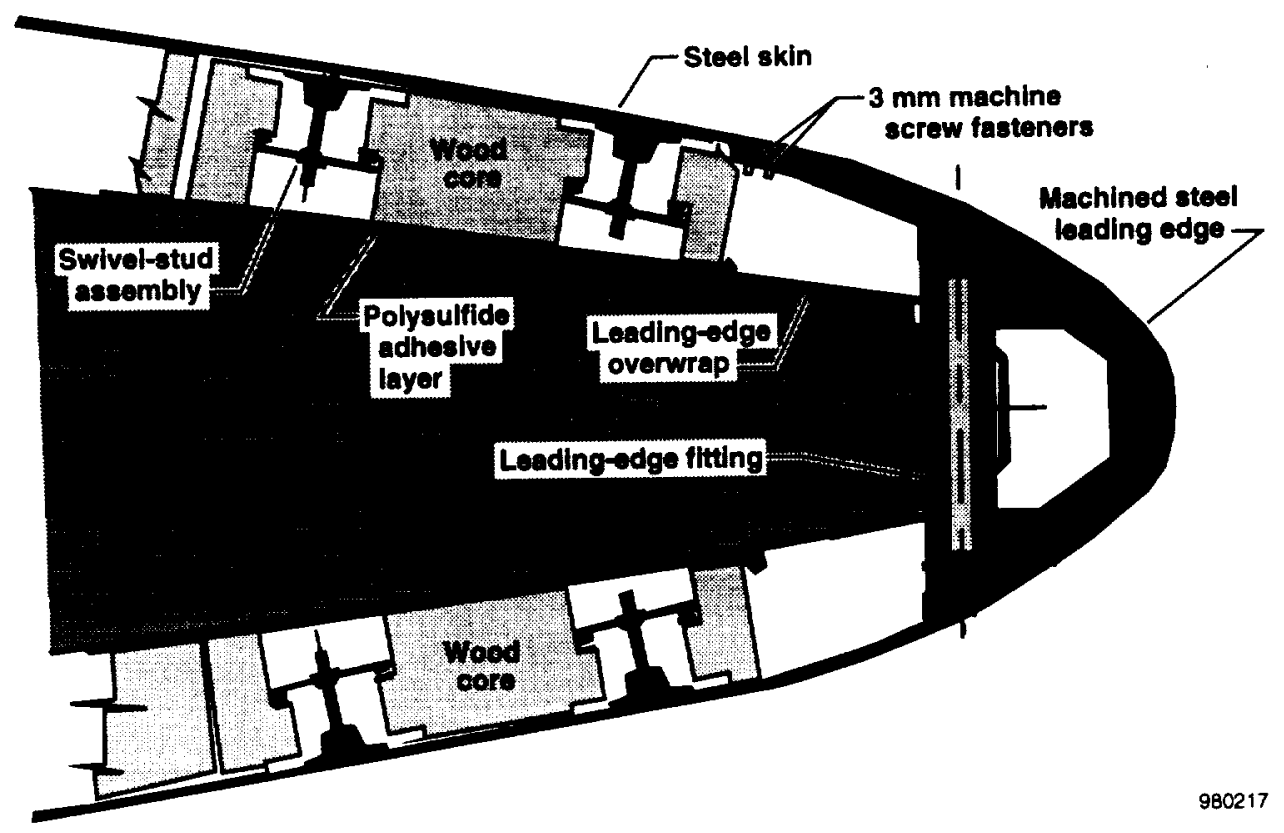

Figure 3. Leading-edge glove structural detail.

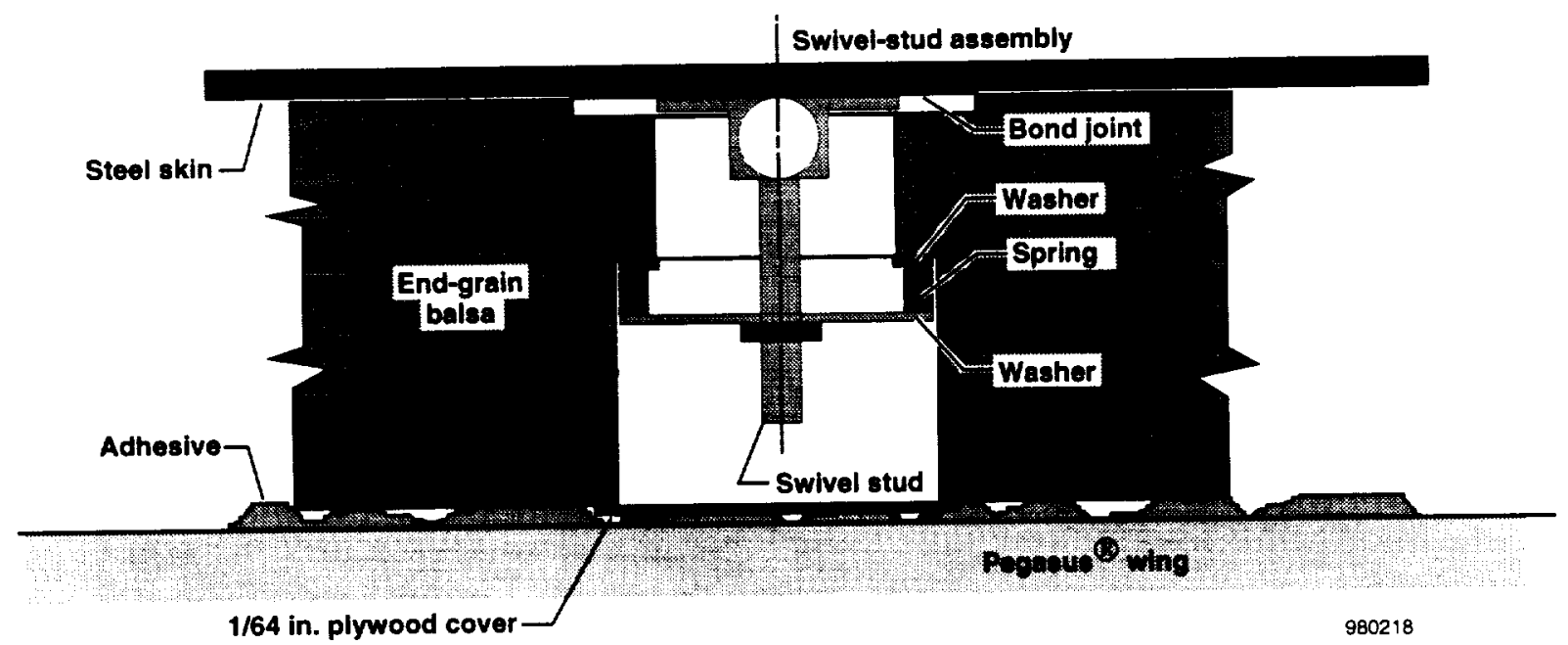

Figure 4. Swivel-stud attachment assembly. 


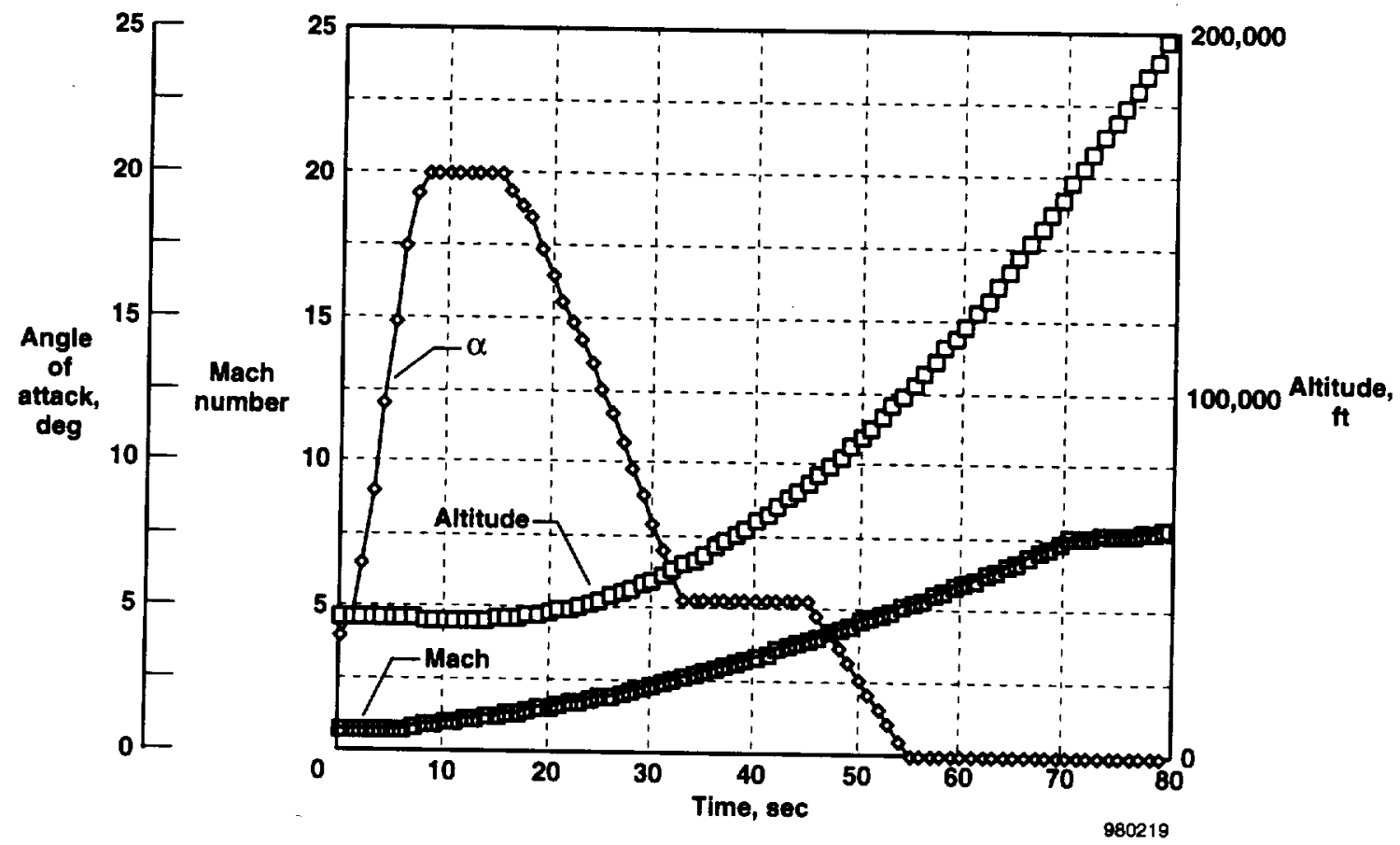
Figure 5. Flight trajectory parameters of Mach number, angle of attack, and altitude for the first stage of the Pegasus ${ }^{\circledR}$
vehicle.

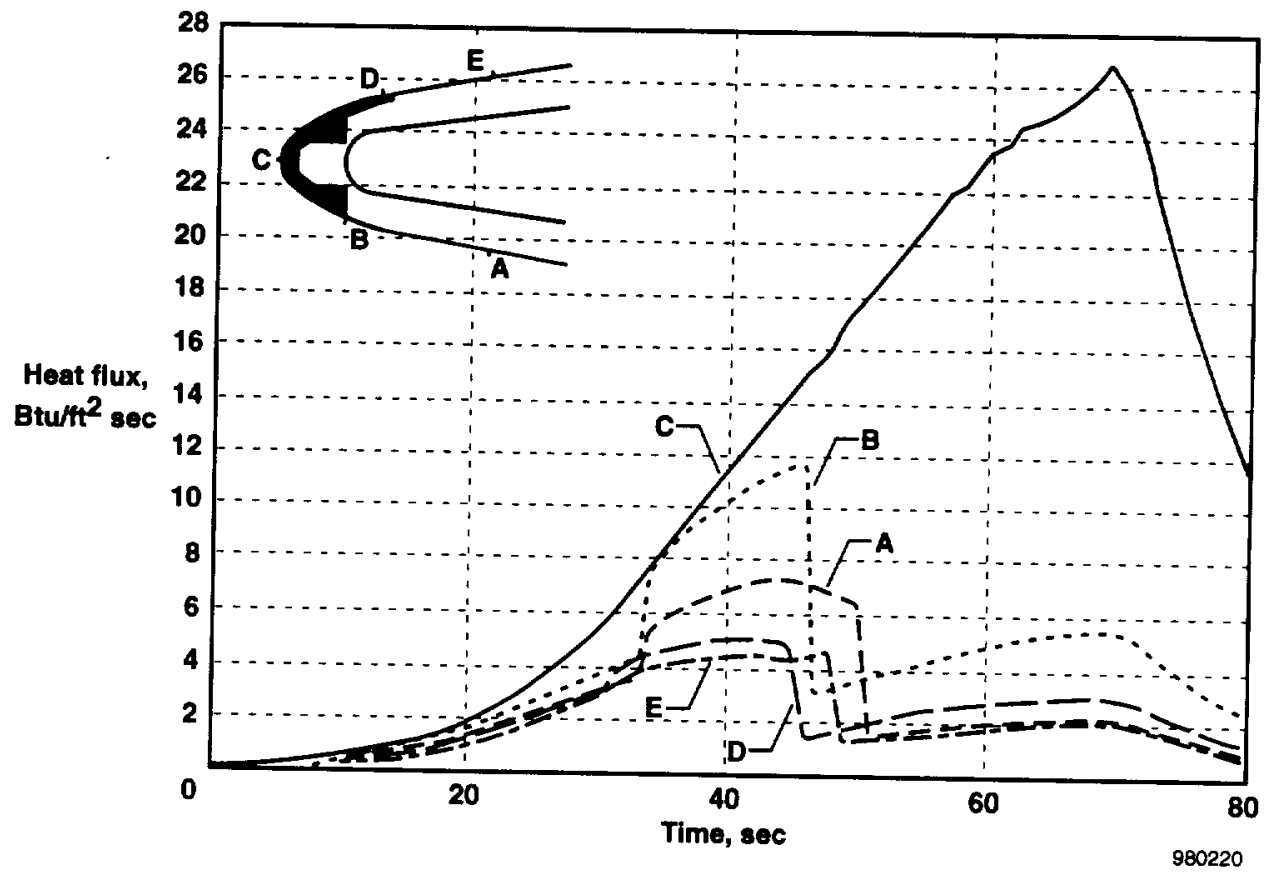

Figure 6. Predicted external aerodynamic heating rates at selected locations on the glove structure. 


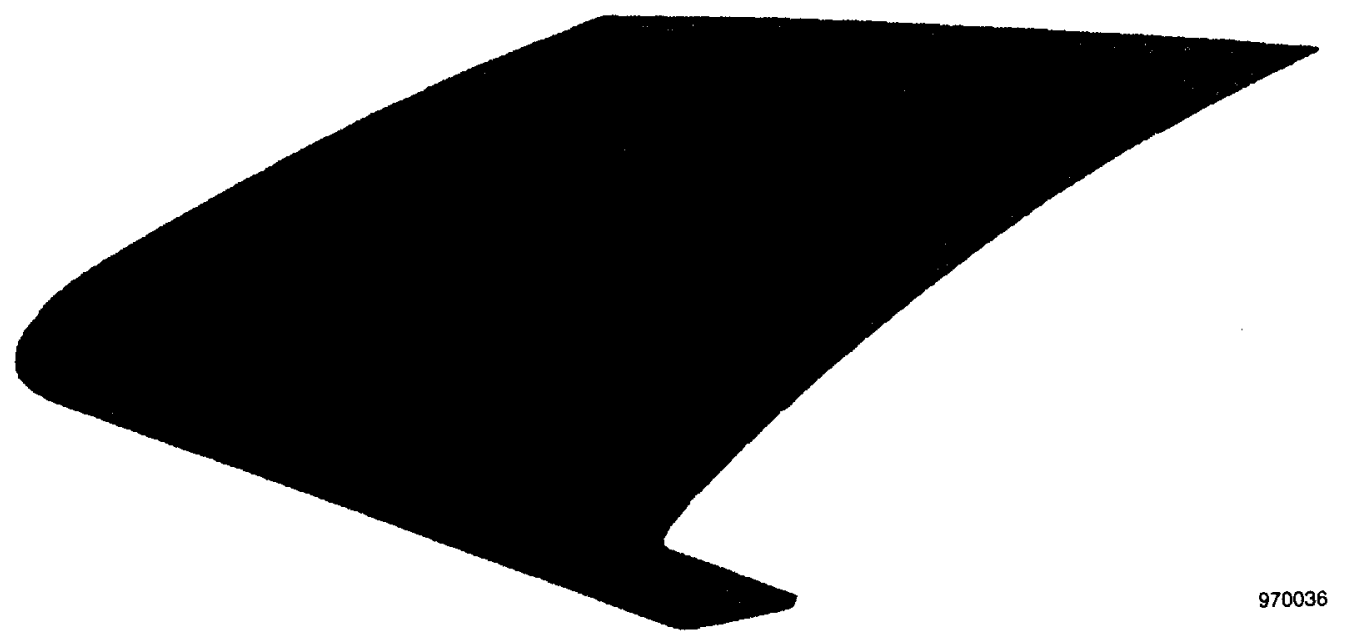

Figure 7. Isometric view of the three-dimensional finite-element thermal analysis model of glove.

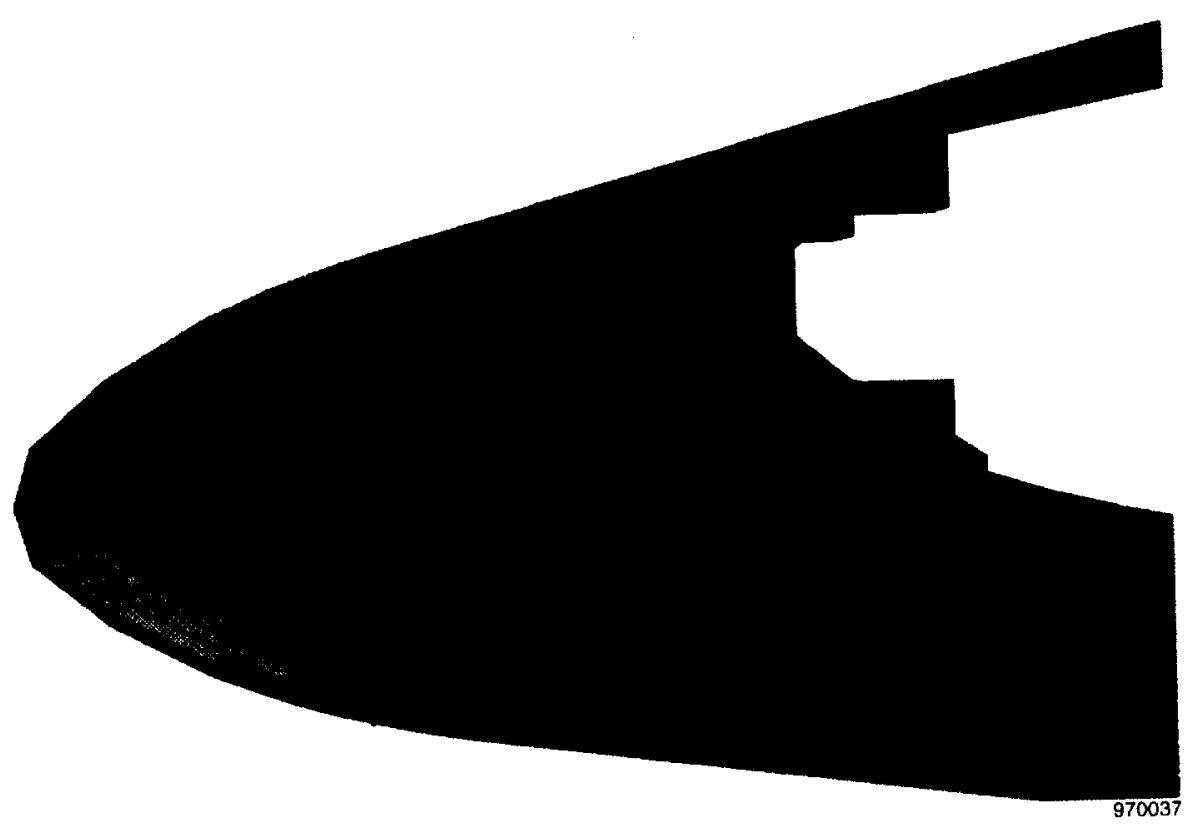

Figure 8. View looking in the three-dimensional glove model. 


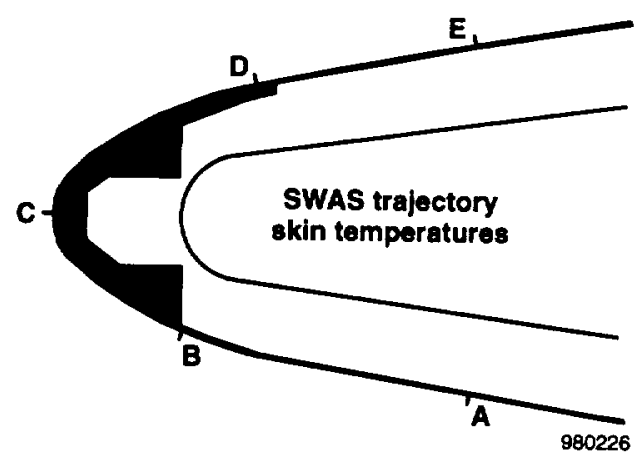

(a) Selected locations.

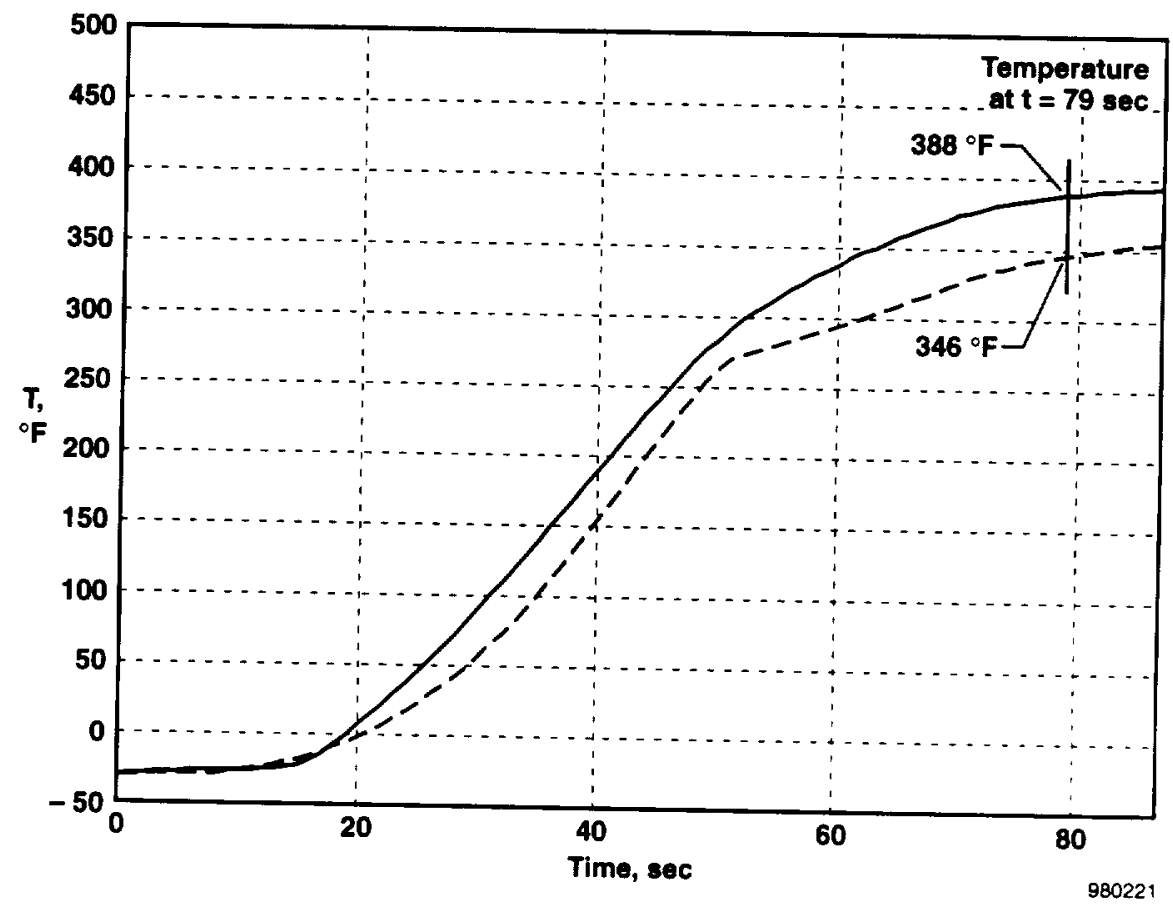

(b) Location A.

Figure 9. Comparisons of surface temperatures at selected locations on glove structure. 


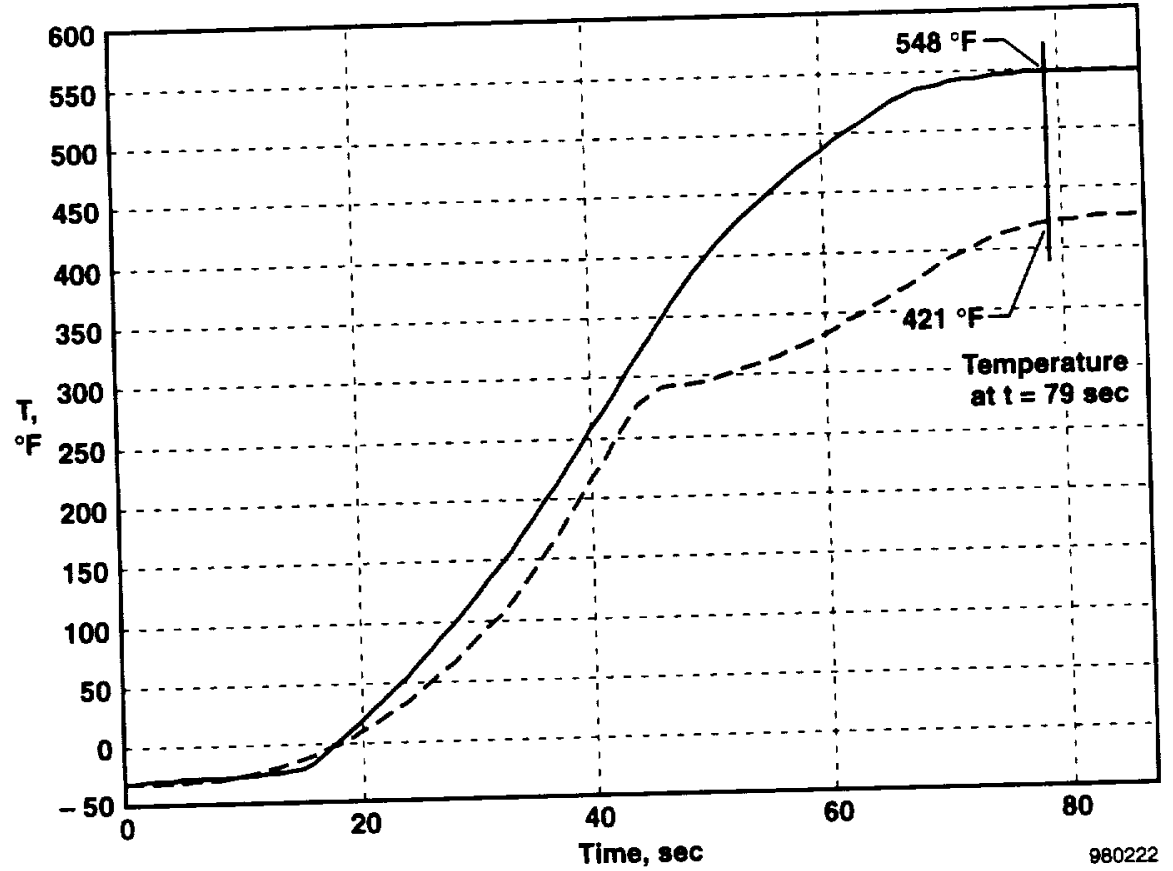

(c) Location B.

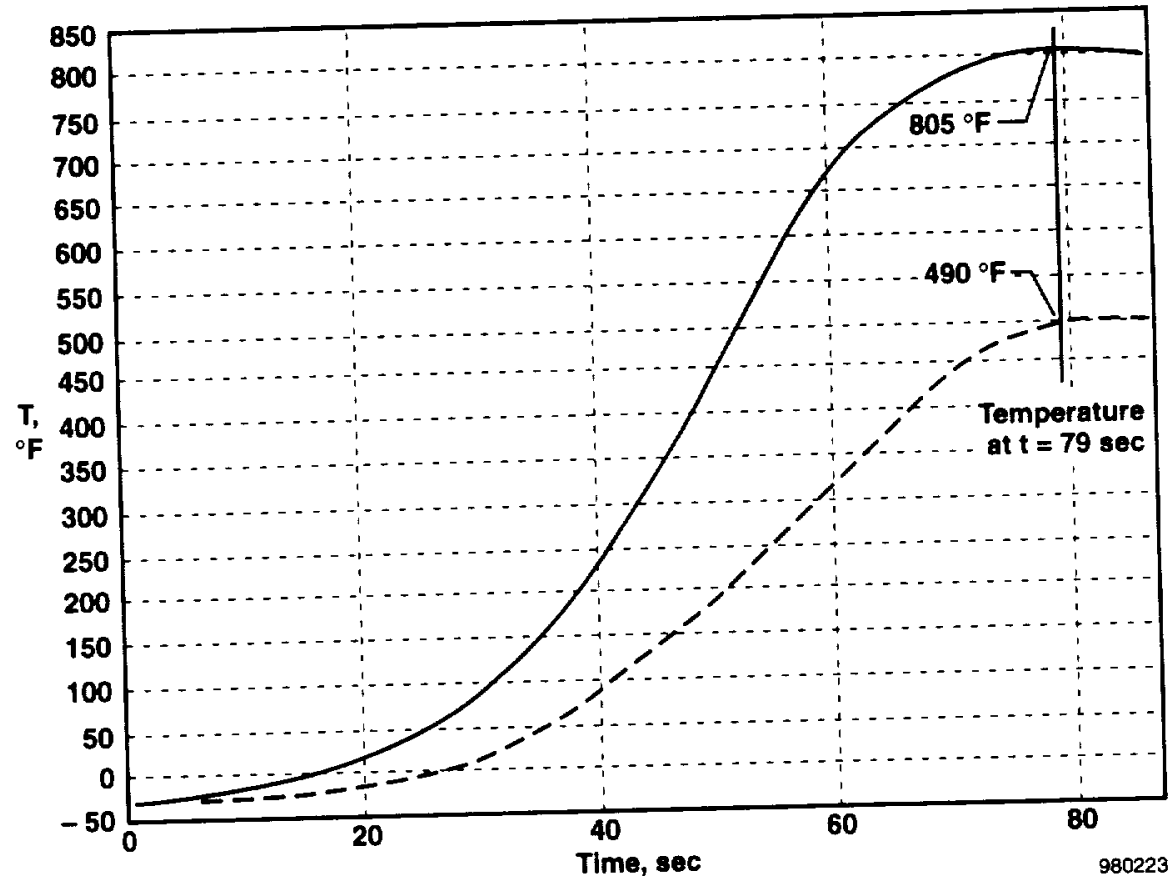

(d) Location $\mathrm{C}$.

Figure 9. Continued. 


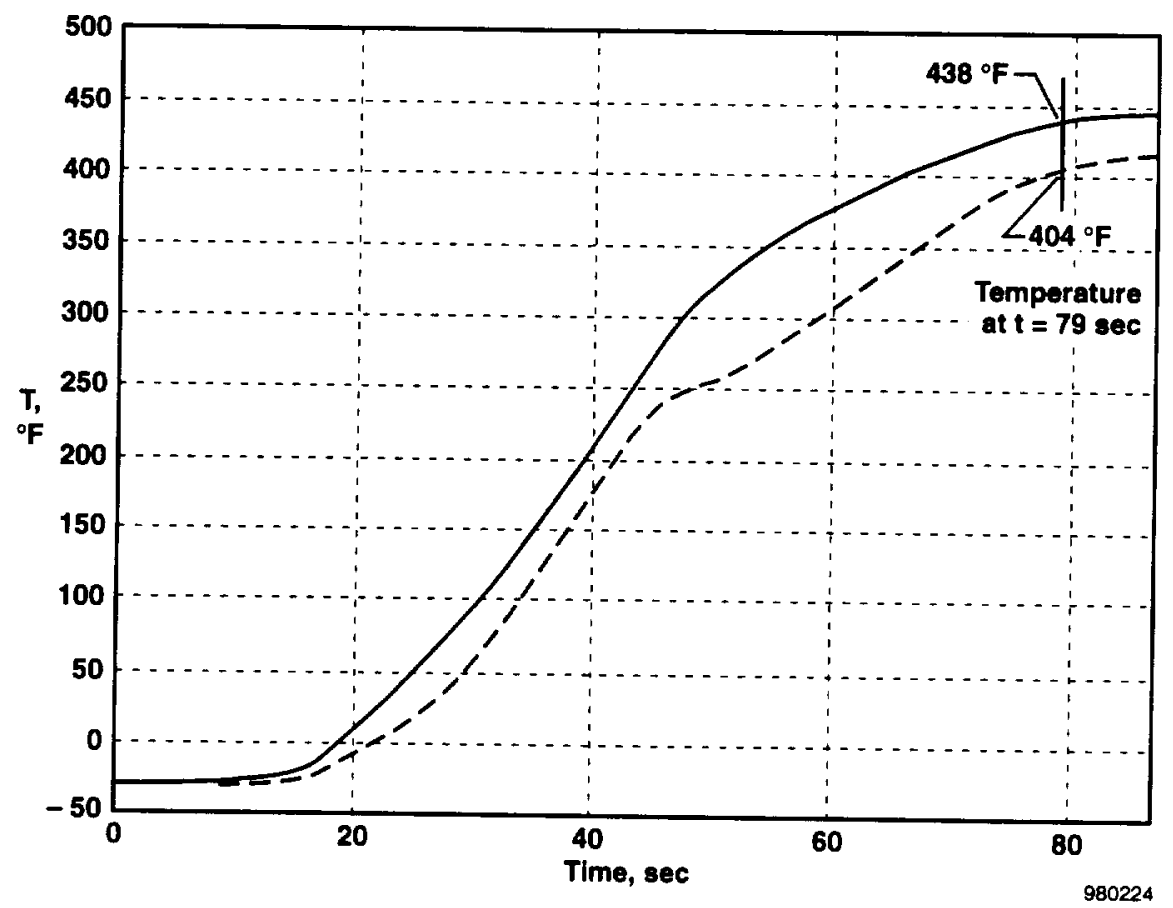

(e) Location D.

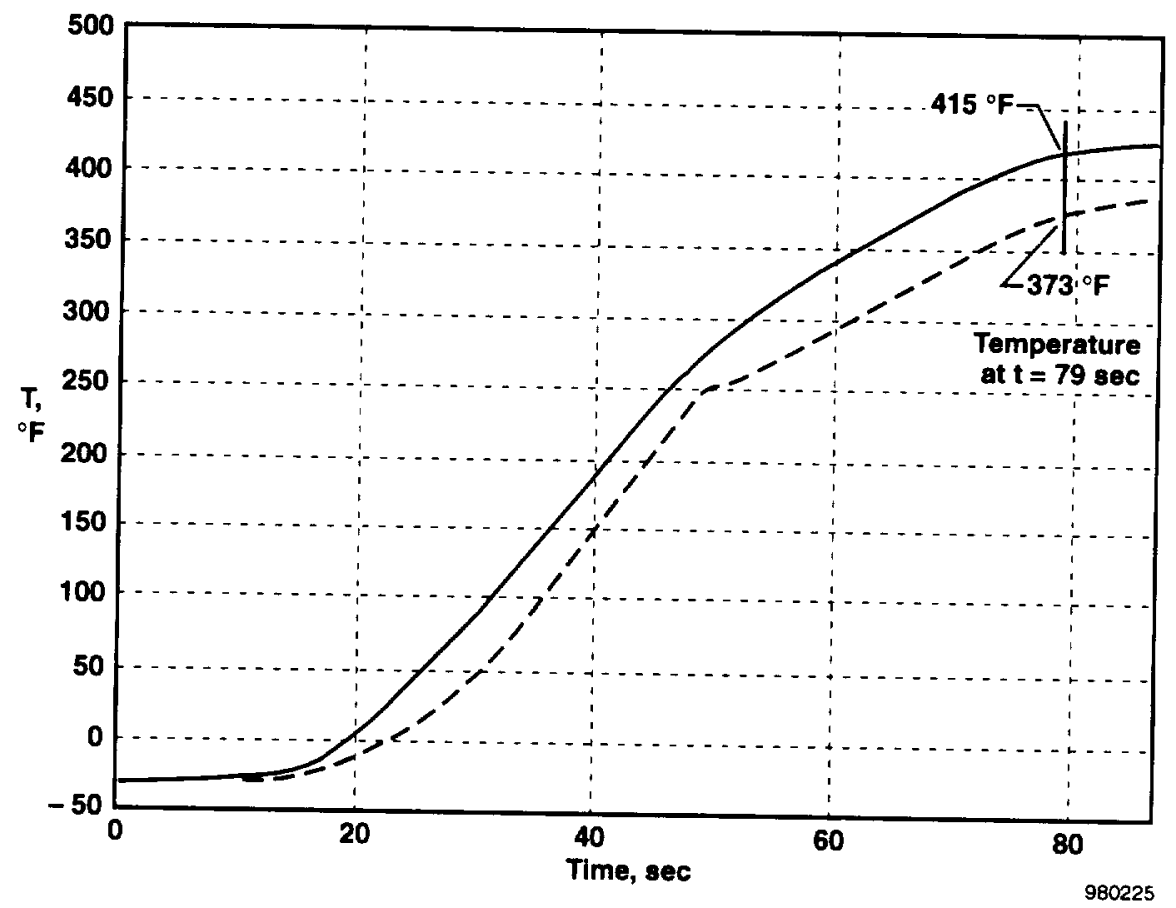

(f) Location E.

Figure 9. Concluded. 


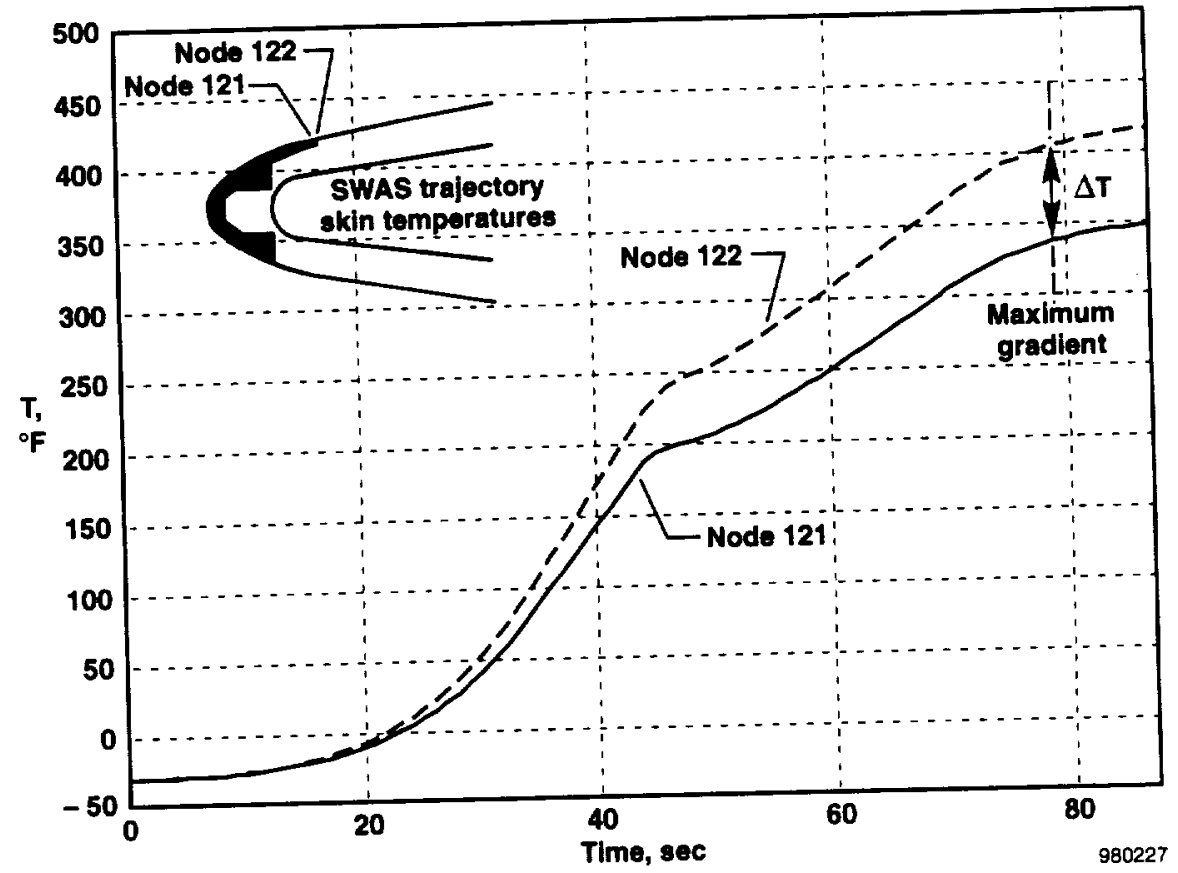

Figure 10. Surface temperature comparisons for two nodes on thick- and thin-skin thickness of the glove structure.

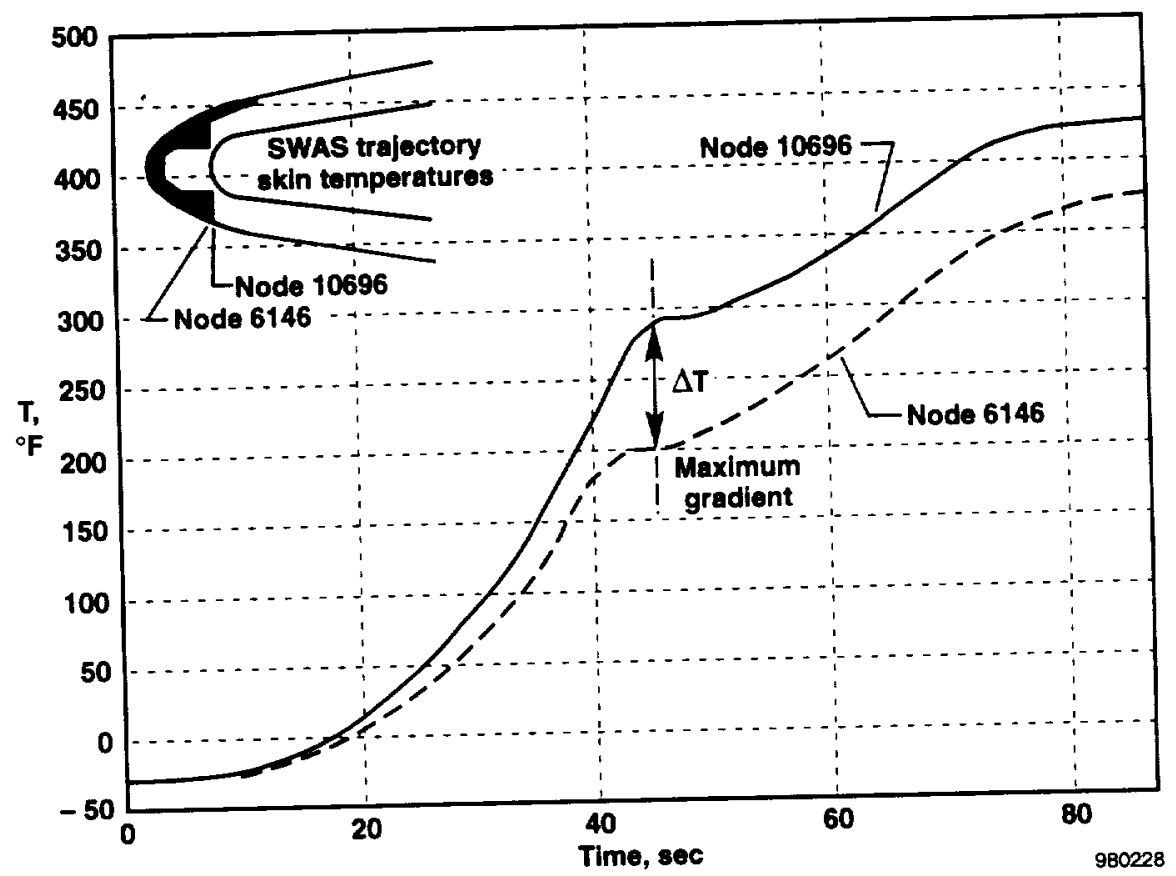

Figure 11. Comparisons of surface temperatures near the bolt location on thick- and thin-skin thickness of the glove structure. 


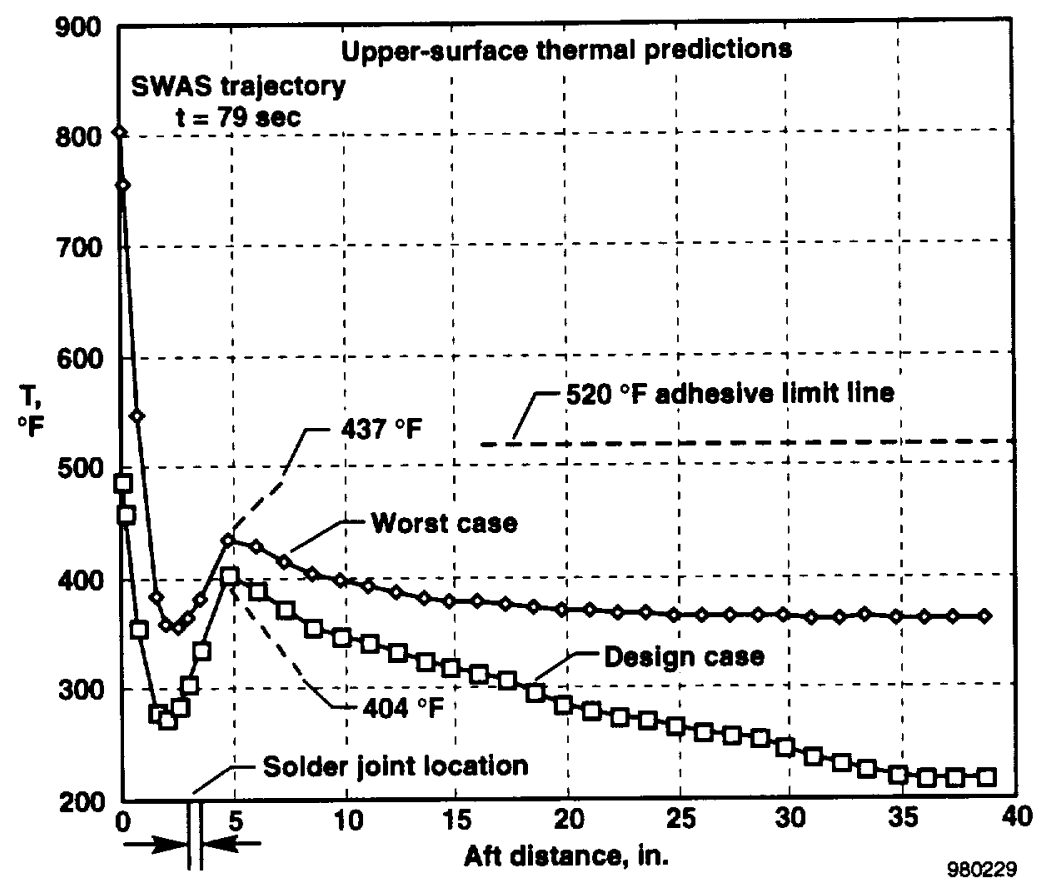

Figure 12. Upper-surface temperature distribution on the glove structure at $t=79 \mathrm{sec}$.

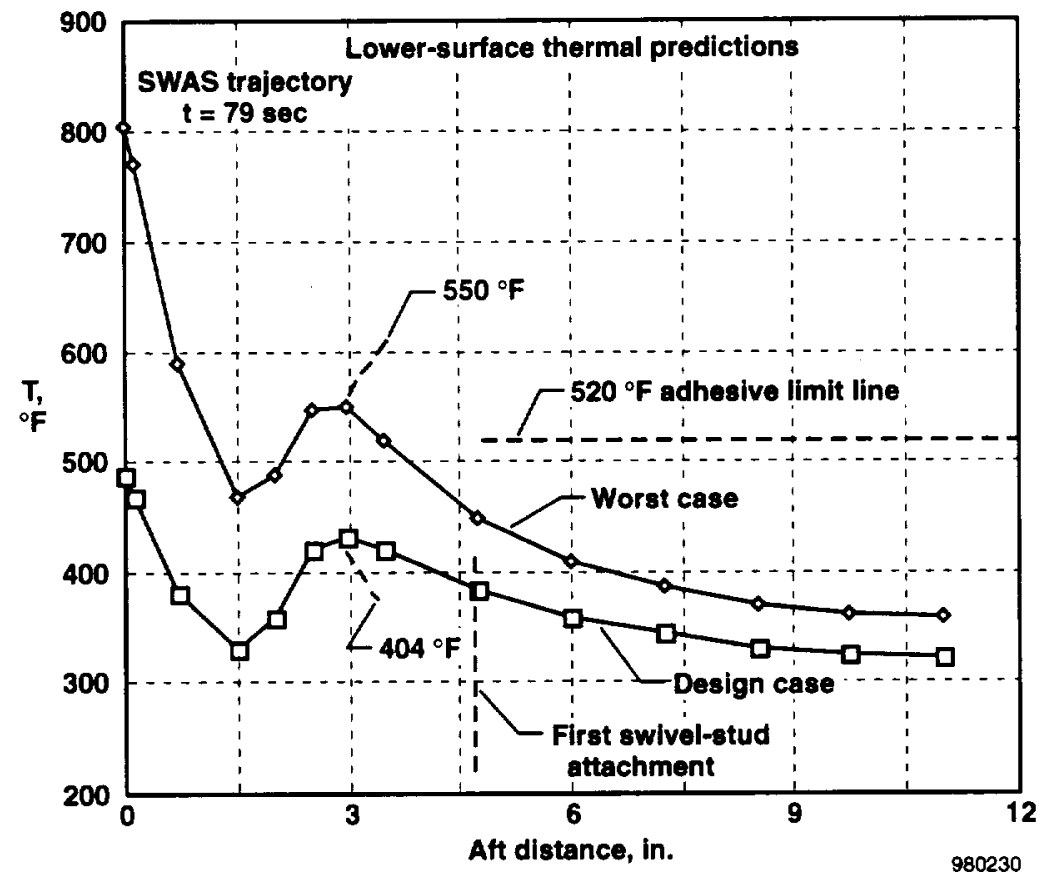

Figure 13. Lower-surface temperature distribution on the glove structure at $t=79 \mathrm{sec}$. 


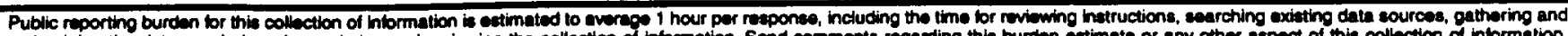

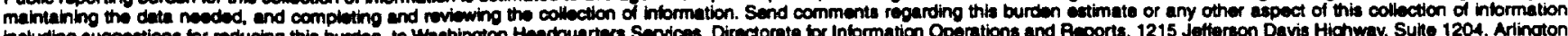
VA $22202-430$, and to the Office of Management and Budget, Paperwork Reduction Project (0704-0188), Washington, DC 20503.

\begin{tabular}{|l|l|l}
\hline 1. AGENCY USE ONLY (Leave blank) & $\begin{array}{l}\text { 2. REPOFT DATE } \\
\text { June } 1998\end{array}$ & $\begin{array}{l}\text { 3. REPOFT TrPE AND DATES COVEAED } \\
\text { Technical Memorandum }\end{array}$ \\
\hline
\end{tabular}

4.TILE ANO SUATILE

June 1998

5. FUNDINO NUMBERS

Thermal Analysis of a Metallic Wing Glove for a Mach-8 Boundary-

Layer Experiment

6. AUTHOR(S)

WU 529-60-24-00-17-00-DOC

Leslie Gong and W. Lance Richards

7. PERFOAMING ORGAMIZATION NAME(S) AND ADDRESS(ES)

NASA Dryden Flight Research Center

P.O. Box 273

Edwards, California 93523-0273

8. PERFOAMING OHGANIZATION

REPOAT NUMBER

H-2259

10. SPONSOAINCMONTORING

MOENCY REPORT MUMBER

National Aeronautics and Space Administration

Washington, DC 20546-0001

NASA/TM-1998-206555

\section{SUPPLEMENTARY NOTES}

Presented at 7th AIAAAMSE Joint Thermophysics and Heat Transfer Conference, June 15-18, 1998, AIAA-98-2580.

12a. DISTRIBUTIONAVALABILTY STATEMENT

Unclassified-Unlimited

Subject Category 34

13. ABSTRACT (Maximum 200 wordo)

A metallic "glove" structure has been built and attached to the wing of the Pegasus ${ }^{\circledR}$ space booster. An experiment on the upper surface of the glove has been designed to help validate boundary-layer stability codes in a free-flight environment. Three-dimensional thermal analyses have been performed to ensure that the glove structure design would be within allowable temperature limits in the experiment test section of the upper skin of the glove. Temperature results obtained from the design-case analysis show a peak temperature at the leading edge of $490^{\circ} \mathrm{F}$. For the upper surface of the glove, approximately 3 in. back from the leading edge, temperature calculations indicate transition occurs at approximately $45 \mathrm{sec}$ into the flight profile. A worst-case heating analysis has also been performed to ensure that the glove structure would not have any detrimental effects on the primary objective of the Pegasus ${ }^{\circledR}$ launch. A peak temperature of $805^{\circ} \mathrm{F}$ has been calculated on the leading edge of the glove structure. The temperatures predicted from the design case are well within the temperature limits of the glove structure, and the worst-case heating analysis temperature results are acceptable for the mission objectives.

\section{SUBJECT TERMS}

Aerodynamic heating, Boundary layer transition, Finite element modeling, Hypersonics, Pegasus ${ }^{\circledR}$, Thermal analysis

\begin{tabular}{|l|l|}
\hline 17. SECUATY CLASSIFICATION & 18. SECUATY CLASSIFICATION \\
OF REPORT & OF THIS PAGE \\
Unclassified & Unclassified \\
\hline
\end{tabular}

19. SECURTY CLASSIFICATION
OF ABSTRACT
Unclassified

Unclassified
15. NUMBEA OF PACES 21

16. PAICE CODE A03

20. LMMTATION OF ABSTRACT

Unlimited

Standard Form 298 (Rev. 2-89) Procertbed by ANSI Sid. 230-18 